\title{
Cooperativity, cage effect and hopping diffusion in supercooled liquids and glasses
}

\author{
A.S.Bakai, N.P.Lazarev \\ National Science Center Kharkov Institute of Physics and Technology \\ 1 Akademichna Str., 61108 Kharkov, Ukraine
}

Received February 10, 2003

\begin{abstract}
Molecular dynamic simulations of structure, thermodynamic and kinetic properties of model metallic $\mathrm{Ag}-\mathrm{Cu}$ alloy are performed to elucidate its behavior at glass transition. In spite of small variations of inherent structure of the alloy the relaxation kinetics undergo dramatic changes at the glass transition. The time dependences of the mean square displacements and the non-Gaussianity parameter show the signs of anomalous diffusion in an intermediate time region. The analysis of time evolution of van Hove correlation function indicates the existence of both jump displacements and short-range cooperative atomic rearrangements. Below $T_{\mathrm{g}}$ these cooperative rearrangements do not contribute to a long-range diffusion but they still dominate the relaxation at short time.
\end{abstract}

Key words: glass transition, metallic alloys, cooperativity, anomalous diffusion

PACS: 61.20.Ja, 61.20.LC, 64.70.Pf

\section{Introduction}

In a wide temperature range above the glass transition temperature $T_{\mathrm{g}}$ the diffusion rate and viscosity do not obey the Arrhenius law. The Vogel-Fulcher-Tamman empiric formula gives a better fit of these quantities above $T_{\mathrm{g}}$. The physical nature of this phenomenon is more or less clear. Due to the interactions the molecular configurations become more and more correlated on short and medium ranges as the temperature decreases. The molecules cooperatively form deep potential wells (cages) which can be rearranged cooperatively. The idea concerning the cooperatively rearranged domains dates back to Adams and Gibbs [1] and Gibbs and DiMarzio [2] papers. A further importance of the cage effect in the supercooled liquid relaxations was underlined by Goldstein [3]. One can find a nice review of this problem and references in [4]. Within the framework of the mode coupling theory (MCT) [5] a constructive base of the cage effect was given. The equations considered in [5] 
for the time dependence of density-density pair correlation function have a solution which shows that at a special temperature $T_{\mathrm{c}}$ the dynamic glass transition takes place. At $T_{\mathrm{c}}$ the ergodicity of the system is lost, the relaxation time is infinite

$$
\tau_{\alpha}(T) \sim\left(T-T_{\mathrm{c}}\right)^{-\nu}, \quad \nu \simeq 2
$$

The short-range pair correlation, with $q \sim a^{-1}$, where $q$ is the wave vector, $a$ is the intermolecular distance, becomes non-ergodic first of all at $T_{\mathrm{c}}$. This result is interpreted as the formation of stable cages of a size $\sim a$ at $T_{\mathrm{c}}$. Experimental data do not confirm all predictions of MCT. According to the fits the temperature $T_{\mathrm{c}}$ appears to be about $50 \mathrm{~K}$ above $T_{\mathrm{g}}$ and no divergence of $\alpha$-relaxation time at $T_{\mathrm{c}}$ is observed. Due to that the MCT is interpreted as an idealized model which predicts temperature of the ideal glass transition $T_{\mathrm{c}}$ and fails below $T_{\mathrm{c}}$. Since the cages are formed near this temperature, one has to take into account the hopping process i.e., thermally activated single jumps of molecules from cages. An improved MCT is proposed in [6].

Along with experimental studies of the relaxation processes in supercooled liquids and glasses [7] their molecular dynamics (MD) simulations are widely used in investigating the region of MCT applicability, the cage effect and the role of the hopping process. To this end, we use MD simulations of $60 \mathrm{Ag}-40 \mathrm{Cu}$ alloy in liquid, glassy and crystalline states. The chosen composition corresponds to the eutectic, and thus the crystallization of the supercooled liquid state is slow. MD simulations [8] did not reveal crystallization of this alloy, where the glass transition was identified from the temperature dependence on volume at a constant pressure. The thermal expansion coefficient has a characteristic jump within a narrow temperature range near $T_{\mathrm{g}}$. The glass transition temperature and the width of the transition depend on the cooling rate. These data indicate that the model used is a proper one for more detailed investigations of the glass transition dynamics in metallic alloys. Our starting point is the analysis of the evolution of thermodynamics and the structure near the glass transition. Then, the dynamics of diffusion at different temperatures is examined. The mean square displacements, the van Hove correlation function, the non-Gaussian parameter, the diffusion coefficient and the pair correlation function are obtained as the functions of time.

\section{Simulation method}

We perform MD simulations of $60 \mathrm{Ag}-40 \mathrm{Cu}$ alloy using an empirical many-body potential of the Sutton-Chen type [9], which belongs to the family of embedded atom potentials. The model provides realistic simulations of melting, crystallization and vitrification processes of this system [8]. To get comparable results we use force-field parameters given in [8]. Being in an original form, the potential [9] does not vanish at the cutoff distance. It was slightly modified by additionally introducing a longrange correction of the total energy and local energy densities [10]. The equations of the atomic motion are numerically integrated by a velocity Verlet algorithm with 
the time steps of 1-4 fs. The wider time step is used for annealing of the samples the narrower one is proper for measurements.

The MD simulation starts with a cubic box containing 16380 atoms randomly arranged in the face centered cubic lattice subject to periodic boundary conditions. Berendsen's method of constant temperature and constant pressure dynamics is employed [11]. During simulation the box sizes are independently varied in order to keep zero normal stresses on each system axes: $\sigma_{x x}=\sigma_{y y}=\sigma_{z z}=0$.

The chosen alloy of eutectic composition tends to a local decomposition even in a crystalline state. To account for this property a long time annealing of crystalline samples at a temperature close to the melting temperature is preliminary performed. Thus, the crystalline structure is equilibrated. The aged crystalline samples compose the initial state of the system. These samples undergo stepwise heating from $100 \mathrm{~K}$ to $2000 \mathrm{~K}$ with the temperature step $50 \mathrm{~K}$. At each temperature, the system is equilibrated during a time span of more than $0.1 \mathrm{~ns}$ and then the measurements of corresponding thermodynamic and kinetic properties are performed. At the end of the heating, the system is found in a liquid state far above the melting temperature. The following stepwise cooldown brings the system to a supercooled liquid state and further to a glassy state. As the temperature decreases, the structural relaxation times of the liquid are rapidly increased. Therefore, we correspondingly boost the aging time at each temperature step from $0.1 \mathrm{~ns}$ at high temperatures up to $10 \mathrm{~ns}$ in the temperature range of glassing. Thereby, an effective cooling rate of about $2 \times 10^{9} \mathrm{~K} / \mathrm{s}$ is obtained.

\section{Thermodynamics}

Figure 1 shows the enthalpy of crystalline and liquid states $H$ as the function of temperature $T$. The oscillatory part $3 k_{\mathrm{B}} T$, where $k_{\mathrm{B}}$ is the Boltzmann constant, is subtracted to have an obvious illustration of characteristic parts of $H(T)$ dependencies. The lower solid line in figure 1 corresponds to the crystalline state. The reduced enthalpy slightly increases with temperature due to anharmonic thermal expansion up to the melting temperature, where the enthalpy indicates a transition to the liquid state. The melting temperature of about $T_{\mathrm{m}}=960 \mathrm{~K}$ (experiment gives $1040 \mathrm{~K}$ ) was derived from simulation of the coexisting phases [12]. Dotted line shows a region of perfect crystal overheating which becomes unstable at about $140 \mathrm{~K}$ higher than the melting point.

Upon cooling, the liquid is supercooled until it is transformed into glass at about $T_{\mathrm{g}}=510 \mathrm{~K}$. This is the caloric glassing temperature as defined by the temperature at which an abrupt change of heat capacity $C_{\mathrm{p}}$ takes place (the insert in figure 1). The dashed line in figure 1 shows an extrapolation of liquid enthalpy $H_{\mathrm{L}}^{*}(T)$ to lower temperatures as if the cooling rate was so small that the supercooled liquid did not lose an ergodicity. Notice that the heat capacity of glass (like in the case of crystal) is an increasing function of temperature while the heat capacity of the supercooled liquid decreases with temperature. This feature is typical of simple metallic systems although this is not the case for all liquids [13]. 


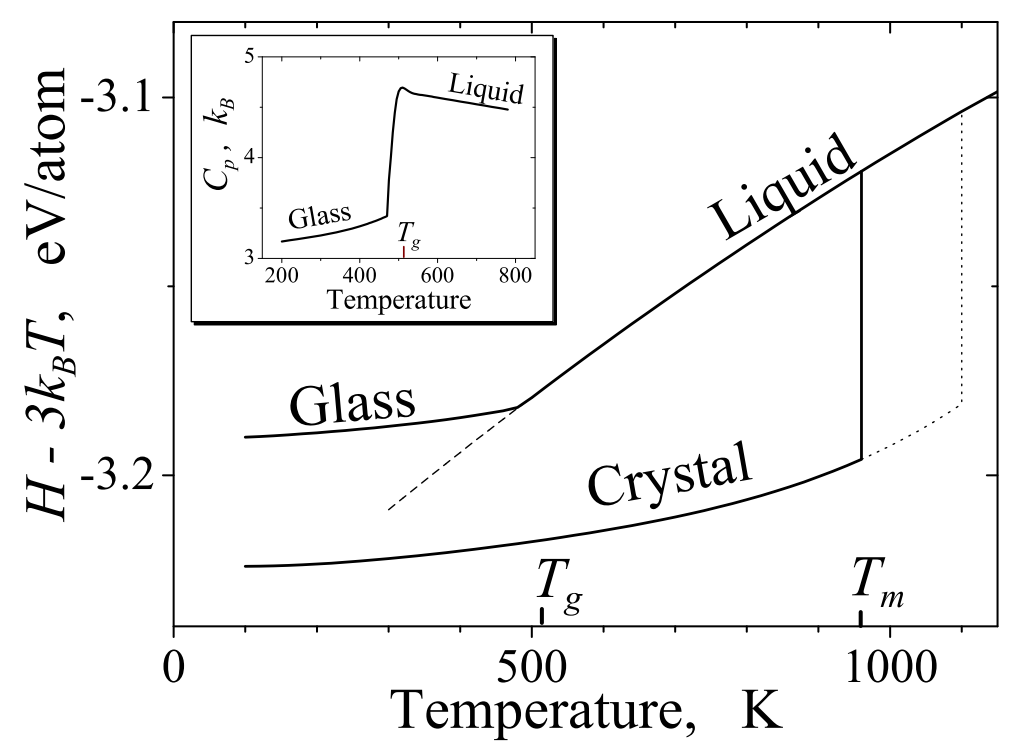

Figure 1. Reduced enthalpy of crystal, liquid and glassy state of $\mathrm{Ag}-\mathrm{Cu}$ alloy. The insert depicts heat capacity behavior below and above glassing temperature $T_{\mathrm{g}}$ at heating.

In the region of glassing temperature $T_{\mathrm{g}}$ the hysteresis on the $H(T)$ dependence takes place at cooling and heating. The area of the hysteresis loop depends on cooling (heating) rate and it decreases with the reduction of the cooling rate. At a cooling rate used in this simulation, the hysteresis area is very small and it was not depicted in figure 1. The small hysteresis indicates that our system is well relaxed in the vicinity of $T_{\mathrm{g}}$.

The dependence of $H(T)$ in figure 1 is isobaric at $P=0$. Therefore, it is easy to get the dependence of free enthalpy by the relation

$$
G(T)=H(T)-T S .
$$

At the melting point $T_{\mathrm{m}}$ the free enthalpy of crystalline and liquid phases coincide: $G_{\mathrm{L}}\left(T_{\mathrm{m}}\right)=G_{\mathrm{C}}\left(T_{\mathrm{m}}\right)$. This gives the entropy difference at this point

$$
\Delta S_{\mathrm{LC}}\left(T_{\mathrm{m}}\right)=\Delta H_{\mathrm{LC}}\left(T_{\mathrm{m}}\right) / T_{\mathrm{m}},
$$

between liquid and crystalline states. Regarding the relation (3) as the initial condition, one can derive the temperature dependence of the entropy difference,

$$
\Delta S_{\mathrm{LC}}(T)=\int_{T_{\mathrm{m}}}^{T} \mathrm{~d}\left[H_{\mathrm{L}}\left(T^{\prime}\right)-H_{\mathrm{C}}\left(T^{\prime}\right)\right] / T^{\prime}
$$

and in the same way the free enthalpy difference $\Delta G_{\mathrm{LC}}(T)$. Figure 2 shows these dependencies. Dashed lines are extrapolations to low temperatures, obtained from liquid enthalpy $H_{\mathrm{L}}^{*}(T)$ at $T>T_{\mathrm{g}}$. The extrapolation of $\Delta S_{\mathrm{LC}}$ gives the Kauzmann temperature $T_{\mathrm{K}}$ from the condition $\Delta S_{\mathrm{LC}}^{*}\left(T_{\mathrm{K}}\right)=0$. Thus, the obtained temperature $T_{\mathrm{K}}=415 \mathrm{~K}$ appears about $20 \%$ lower than the glassing temperature $T_{\mathrm{g}}$, which is 


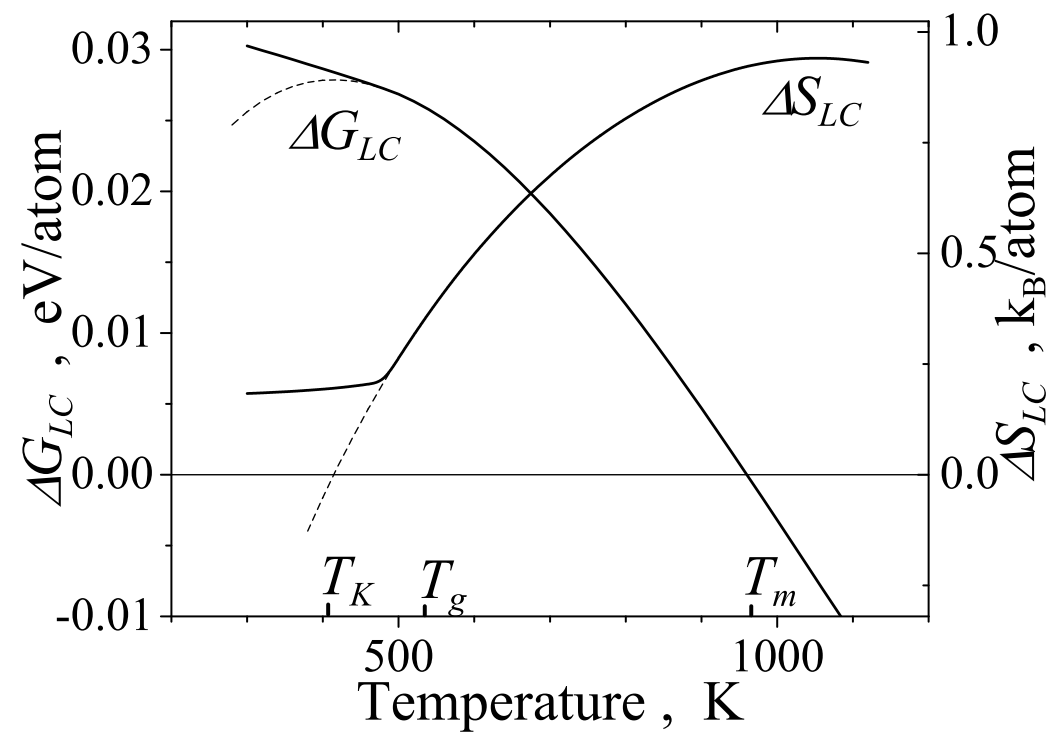

Figure 2. Free enthalpy and entropy difference between liquid and crystalline state. Dashed lines show extrapolation of liquid dependencies to low temperatures.

similar to the case of fragile liquids [13]. The estimated $T_{\mathrm{K}} / T_{\mathrm{g}}$ for many metallic alloys is of the same value (cf. [14]). The Kauzmann temperature is usually interpreted as a lower limit of glassing temperature at the cooling rate approaching zero. Actually this limit in our case cannot be reached because this metallic system is crystallized in finite time. It was found [15] that the crystallization is limited by nucleation and incubation time of the liquid-crystal transformation, which is roughly estimated to be $3 \times 10^{-4} / N$ sec at $T=550 \mathrm{~K}$, where $N$ is the number of atoms in the elementary box. The slow crystallization opens a wide time window for the evolution of the properties of this system in a supercooled liquid and glassy state.

\section{Structure}

Structure properties of the model alloy are analyzed by means of the radial distribution function (RDF) and the common-neighbor analysis (CNA)[16]. To exclude the effect of atomic thermal oscillations, structural configurations have been found of the atomic potential energy minima that correspond to inherent structure configurations [17].

Figure 3 clearly shows that the inherent structures of the liquid and glassy states are almost indistinguishable because the radial distribution functions nearly coincide.

The CNA indicates that there is a large fraction of icosahedral ordering in both supercooled liquid and in glassy state, and this fraction steadily grows with lowering of the temperature. On the contrary, the fraction of "disordered" bonds such as 311 and 322 monotonically decreases with temperature. The representatives of crystalline ordering 422 and 421 are almost independent of temperature. The similar 


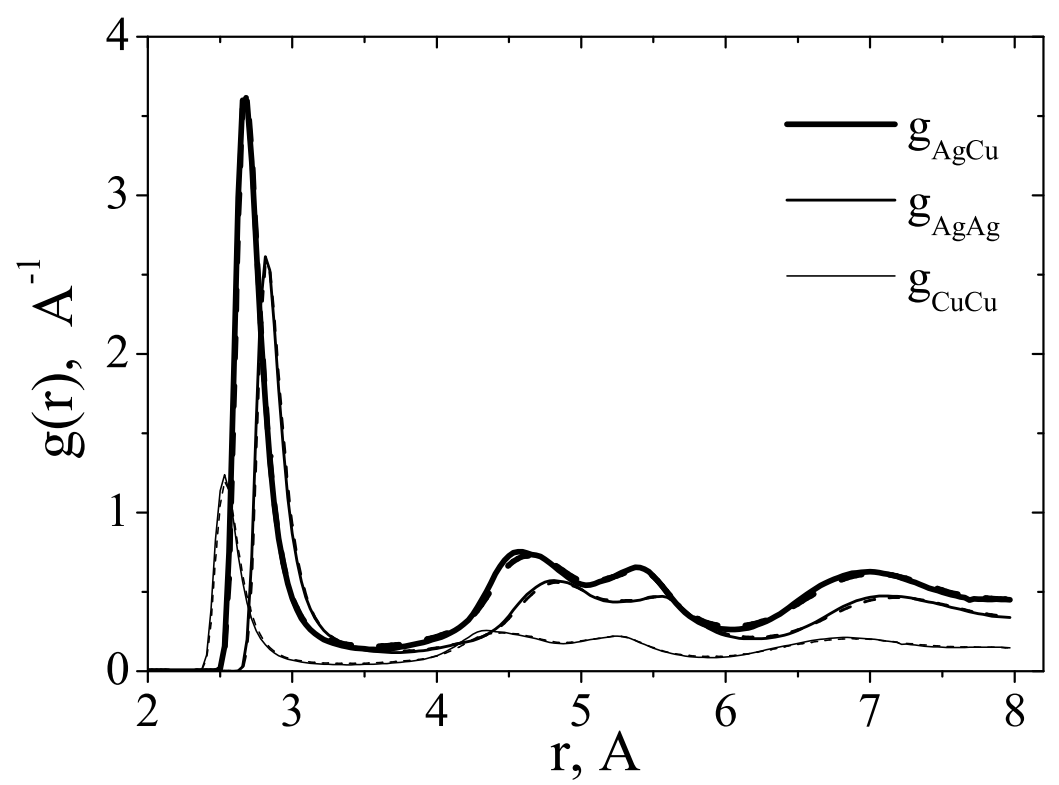

Figure 3. Partial radial distribution functions at two different temperatures. Solid lines: $T=500 \mathrm{~K}$, dashed lines: $T=600 \mathrm{~K}$.

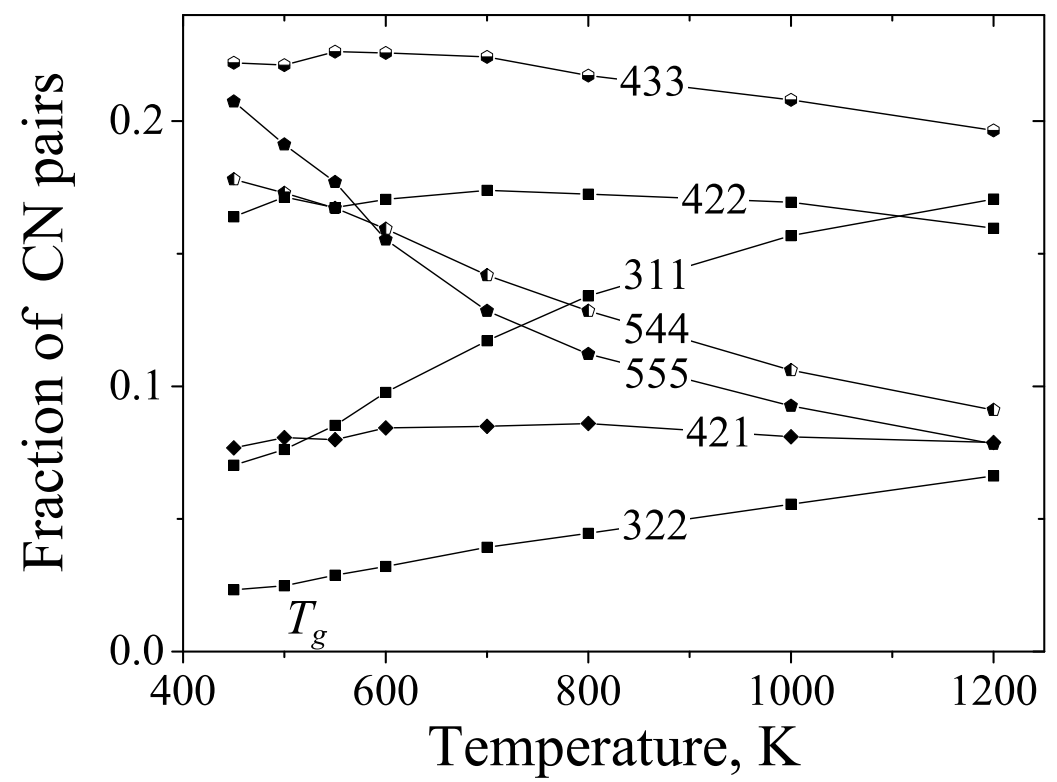

Figure 4. Common-neighbour pairs analysis. 555 - icosahedral bonds, 544 and 433 - distorted icosahedral bonds, 421 and 422 - crystalline bonds. 


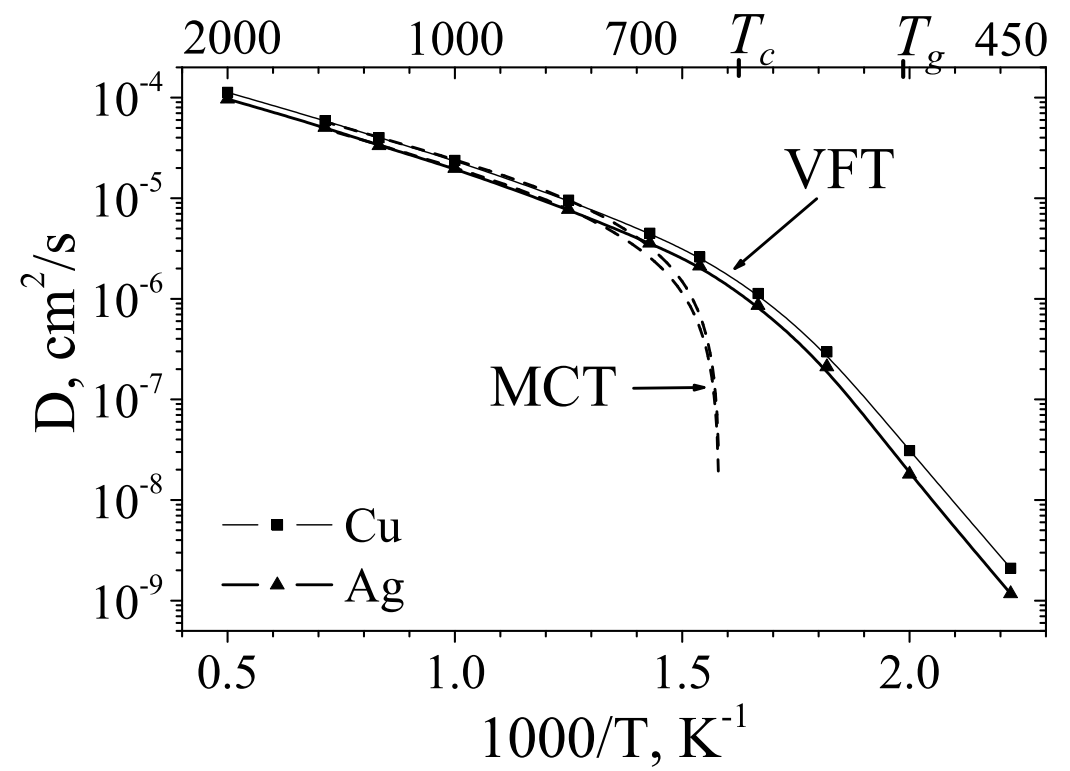

Figure 5. The temperature dependence of diffusion coefficients.

behaviour of short-range ordering was observed in the close composition system [18]. From these temperature dependencies we can conclude that while there is some kink on the indicated dependencies still it is not so evident in order to explain dramatic changes in thermodynamics and kinetics in the vicinity of glassing temperature $T_{\mathrm{g}}$.

It should be noted that both CNA and RDF describe the structure statistically, and some underlying structural features which play a role in the relaxation processes are inaccessible.

\section{Diffusion}

Figure 5 shows the temperature dependence of diffusion coefficients, derived from the time evolution of mean-square atomic displacements

$$
D_{\alpha}(t)=\frac{1}{6} \frac{\partial}{\partial t}\left\langle\left(\vec{r}_{\alpha}^{i}\left(t+t_{0}\right)-\vec{r}_{\alpha}^{i}\left(t_{0}\right)\right)^{2}\right\rangle, \quad \alpha=\mathrm{Ag}, \mathrm{Cu} .
$$

where $\langle\ldots\rangle$ means ensemble averaging over all atoms $i$ and over starting times $t_{0}$. Long time asymptotic of (5) at $t \rightarrow \infty$ gives the diffusion coefficients $D_{\alpha}$ in usual meaning.

Below $T_{\mathrm{g}}$ diffusivity decreases several orders of magnitude and this poses difficulties in equilibrating the system.

The diffusional coefficients of both components are similar in the whole temperature range. A smaller $\mathrm{Cu}$ component diffuses a little faster and the difference of diffusivities increases with the lowering of temperature only from $16 \%$ at $2000 \mathrm{~K}$ to $80 \%$ at $450 \mathrm{~K}$, whereas the total diffusion changes here for 5 orders of magnitude.

There are three temperature regimes on the dependence. The high and low temperature asymptotes behave according to the classical Arrhehius law $D(T)=$ 


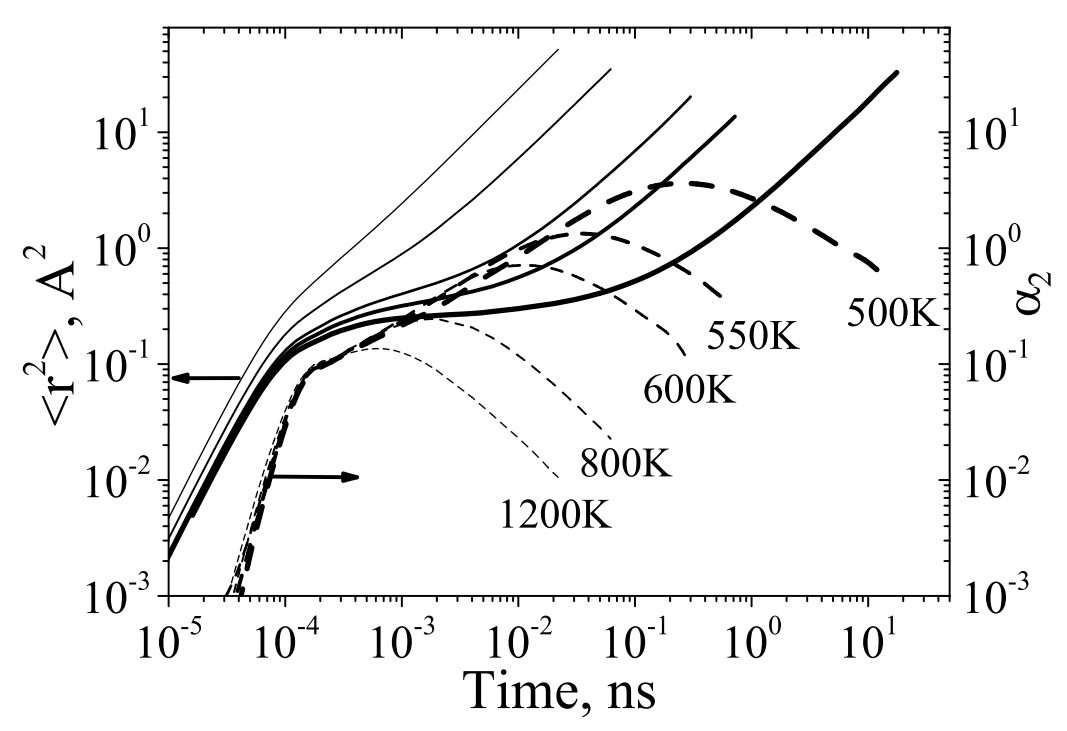

Figure 6. Time dependence of mean-square displacements and non-Gaussianity parameter of $\mathrm{Cu}$ atoms at different temperatures.

$D_{0} \exp \left(-E / k_{\mathrm{B}} T\right)$ with very different pre-exponential factors and activation energies. In the intermediate temperature regime about $(1 \div 1.6) T_{\mathrm{g}}$, the diffusion drops faster than it is described by the Arrhehius law. This dependence can be well fitted by Vogel-Fulcher-Tamman law:

$$
D(T)=D_{0} \exp \left[-T_{1} /\left(T-T_{0}\right)\right]
$$

with $T_{0}=316 \mathrm{~K}$. For $\mathrm{Cu}, T_{1}=1607 \mathrm{~K}, D_{0}=2.7 \times 10^{-4} \mathrm{~cm}^{2} / \mathrm{s}$; and for $\mathrm{Ag}$, $T_{1}=1675 \mathrm{~K}, D_{0}=2.5 \times 10^{-4} \mathrm{~cm}^{2} / \mathrm{s}$.

Mode-coupling temperature [5] was evaluated from fitting the high temperature data. It was found that $T_{\mathrm{c}}=632 \mathrm{~K}$, if we include the data above $1000 \mathrm{~K}$ in the fitting. The inclusion of the points at lower temperatures shifts $T_{\mathrm{c}}$ downward while deteriorating the fit. However, we do not see any significant changes in structural or in relaxation properties in the vicinity of $T_{\mathrm{c}}$. Thus, the mode coupling fit seems improper for the system under consideration.

Figure 6 shows the time dependences of the mean-squared atomic displacements and the so-called non-Gaussianity parameter: $\alpha_{2}=0.6\left\langle\vec{r}^{4}\right\rangle /\left\langle\vec{r}^{2}\right\rangle^{2}-1$ [19].

Here, we plot by solid lines the mean-squared displacements of $\mathrm{Cu}$ atoms and by dashed lines we show the non-Gaussianity parameters. From $\left\langle\vec{r}^{2}(t)\right\rangle$ in the glassy state one can see that ballistic motion, $\left\langle\vec{r}^{2}\right\rangle \sim t^{2}$, dominates at short times. At intermediate times, $\left\langle\vec{r}^{2}\right\rangle$ goes to nearly a plateau and at long times normal diffusion with $\left\langle\vec{r}^{2}\right\rangle \sim t$ takes place. With the temperature increasing, the plateau becomes shorter and at higher temperatures in the liquid state it disappears altogether and the diffusion follows immediately after the ballistic one. On examining the $\left\langle\vec{r}^{2}(t)\right\rangle$ dependence in glassy state more carefully, we find that the plateau is not totally flat but increases slowly with time roughly as a power law with a small exponent. In the time regime of the plateau, the non-Gaussianity parameter increases approximately 


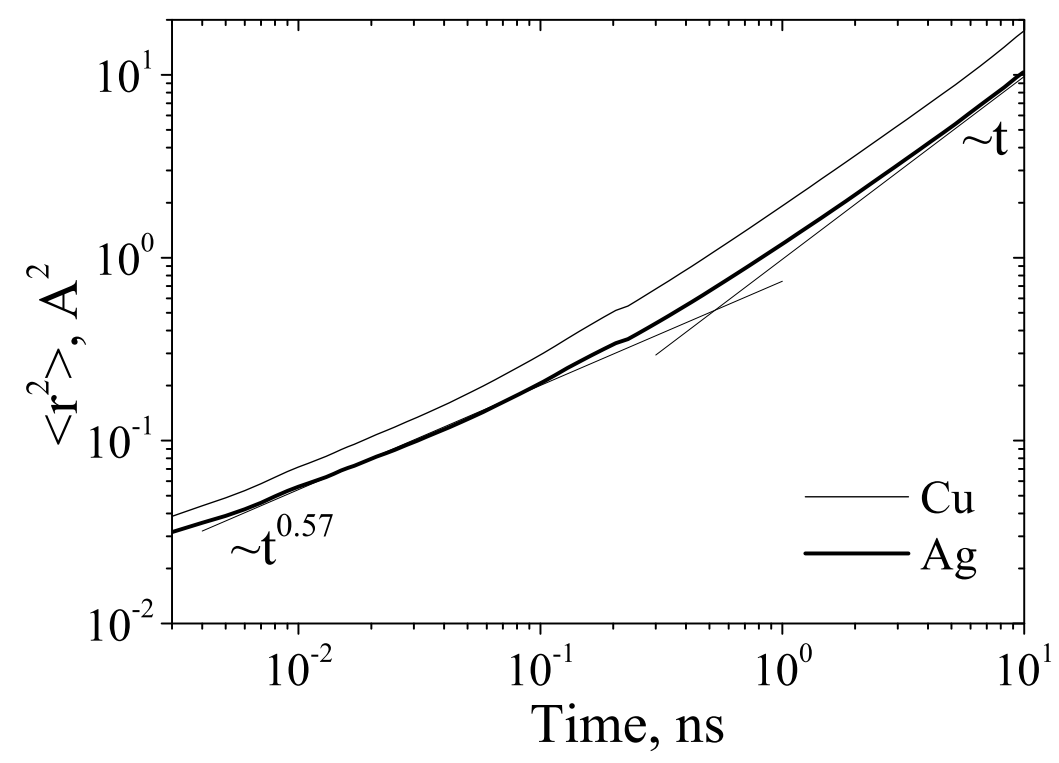

Figure 7. Time dependence of inherent diffusion without oscillatory part in a glassy state $(T=500 \mathrm{~K})$.

as $t^{1 / 2}$, at all temperatures, from glassy state to the high temperature liquids. For low temperature this dependence persists up to the $3-4$ orders of magnitude in time. This feature was recently observed for different systems [21] and the origin of this scaling is not yet clear.

Figure 7 demonstrates the change from anomalous diffusion with $\left\langle\vec{r}^{2}(t)\right\rangle \sim t^{\beta}$ and $\beta<1$ to normal diffusion with $\beta=1$. In the anomalous diffusion time regime the time dependence of $\left\langle\vec{r}^{2}(t)\right\rangle$ is similar to that of the non-Gaussianity parameter.

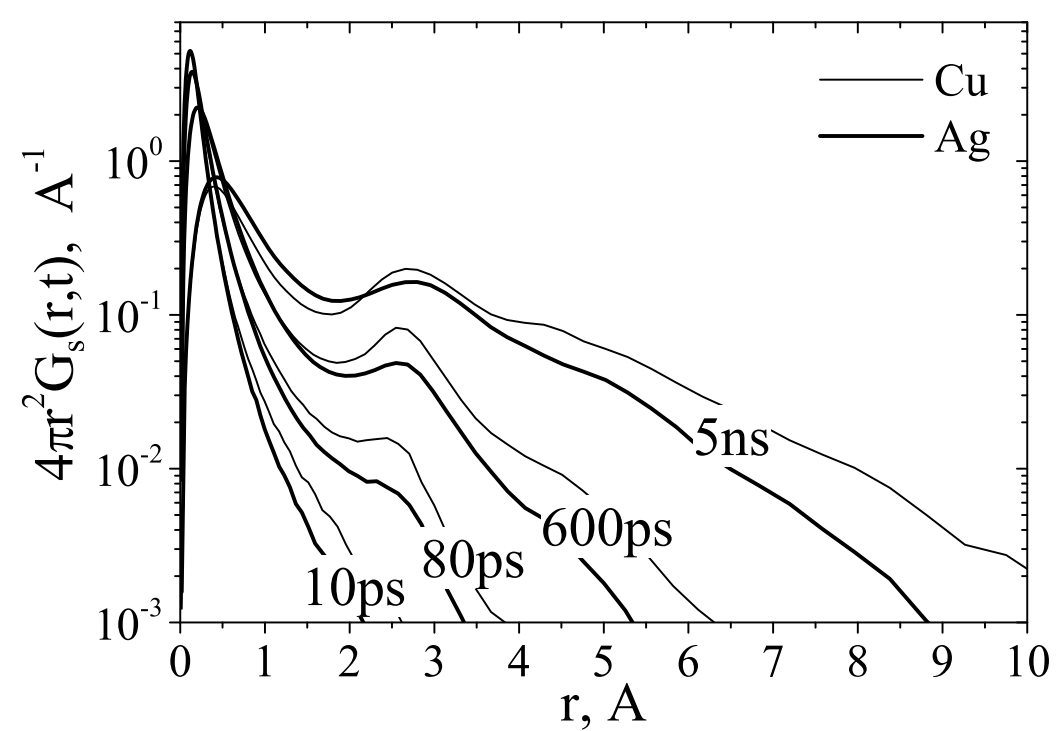

Figure 8. Van Hove correlation function of atomic displacements at a different time in glassy state $(T=500 \mathrm{~K})$. 


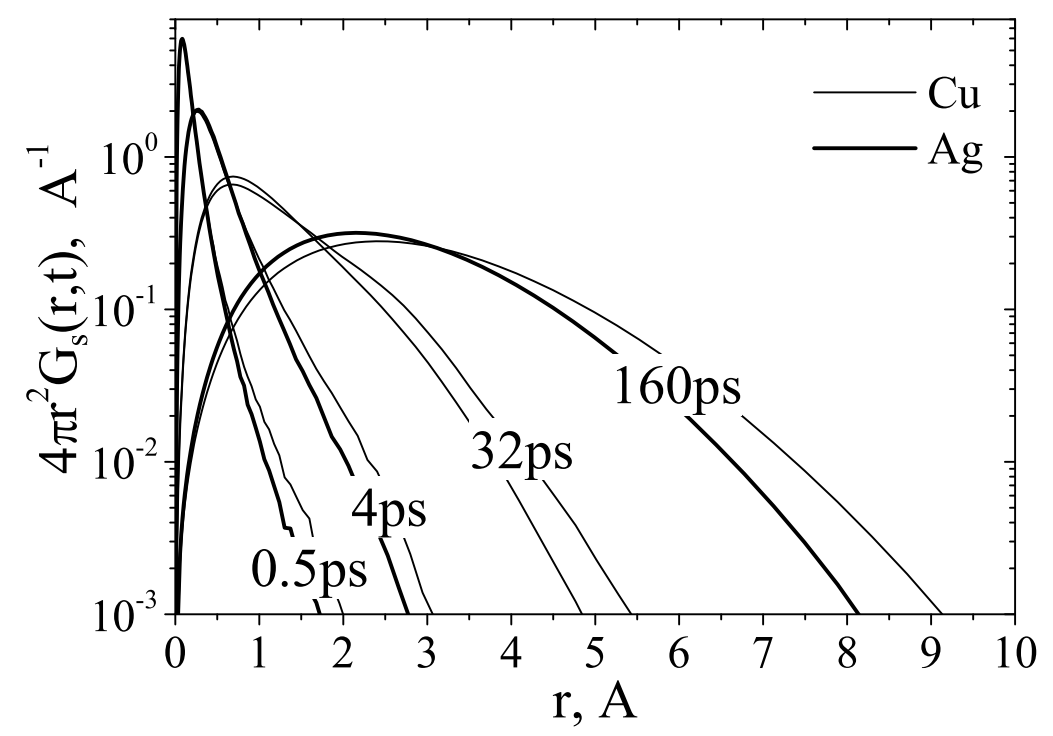

Figure 9. The same as in figure 8 but for supercooled liquid $(T=600 \mathrm{~K})$.

Figures 8 and 9 show the van Hove correlation functions of $\mathrm{Cu}$ and $\mathrm{Ag}$ atoms in the glassy and in the super-cooled liquid states at different times. In the glassy state at short time, only one peak of van Hove function exists at $r<1 \AA$ while at longer time, $t>80 \mathrm{ps}$, an additional peak located at $r \sim 3 \AA$ appears. At $t=5 \mathrm{~ns}$, long tails of van Hove functions for $\mathrm{Ag}$ and $\mathrm{Cu}$ atoms are evident.

An important feature of the van Hove functions presented is that the locations and widths of the first peaks for both types of atoms coincide. It means that this peak corresponds to cooperative rearrangements involving both types of atoms [20]. These cooperative "fluid-like" atomic rearrangements appear to be the main mechanism of short-range diffusion in a glassy state. The second peak and the tail at longer distances for $\mathrm{Cu}$ and $\mathrm{Ag}$ are different. Since the location of the second peak is essentially the same as the location of the first peak of the RDF (figure 3), it is attributed to single jumps of $\mathrm{Ag}$ and $\mathrm{Cu}$ atoms. The tails of the van Hove functions also have to be attributed to the hopping process. The first peak is shifted to larger values of $r$ and broadened at the same time, although the broadening is not as large compared to the second peak and the tail. Hence, the short-range cooperative rearrangements make no significant contribution into the long time diffusion in glass.

The picture is completely different for the supercooled liquid state. The van Hove functions have got just one peak, which shifts to a longer distance $r$ and broadens with the time increasing. Location and height of this peak for $\mathrm{Ag}$ and $\mathrm{Cu}$ coincide but the tails at a longer distance are different. These data lead to the following interpretation. The short time and the long time diffusions in a liquid state are all mainly controlled by cooperative rearrangements involving the nearest neighbors (see also the results presented and discussed in [23]). Due to the hopping process of $\mathrm{Ag}$ and $\mathrm{Cu}$ being different, the long-range tails of their van Hove functions are different. The hopping process at high temperatures was also observed in MD simulations of a two component liquid system in [24]. 


\section{Conclusions}

The relaxation processes in liquid and glassy states of $60 \mathrm{Ag}-40 \mathrm{Cu}$ metallic alloy are investigated. Isobars obtained of the liquid, glassy and crystalline states of this alloy clearly show the existence of a glass transition. No significant changes of the RDF and CNA are observed at a glass transition, while the relaxation kinetics undergo dramatic changes.

The mean square displacements, the van Hove correlation function, the nonGaussianity parameter, the diffusion coefficient and the pair correlation function show that the short time dynamics is stochastic involving the local displacement of the atoms. At a longer time, the hopping of the atoms with larger displacements takes place. The crossover is seen from the pair correlation function. The crossover time from local to longer-range motion turns out to be close to the independent relaxation time of the coupling model (not explicitly shown here). Comparison of the simulation data with MCT has a limited applicability.

It is shown that a longer-range hopping plays a key role in the relaxation dynamics in the glass while cooperative rearrangements with smaller displacements are dominant in the liquid state.

\section{Acknowledgements}

This work was partially supported by Science and Technology Center in Ukraine, Project No. 2047.

\section{References}

1. Adam G., Gibbs J.H. // J. Chem. Phys., 1965, vol. 43, p. 139.

2. Gibbs J.H., DiMarzio E.A. // J. Chem. Phys., 1958, vol. 28, p. 373.

3. Goldstein M. // J. Chem. Phys., 1969, vol. 51, p. 3728.

4. Sillescu H. // J. Non-Cryst. Solids, 1999, vol. 243, p. 81.

5. Gotze W., Sjogren L. // Rep. Prog. Phys., 1992, vol. 55, p. 241.

6. Gotze W. // J. Phys.: Condens. Matter., 1999, vol. 11, p. A1.

7. Angell C.A., Ngai K.L., McKenna G.B., McMillan P.F., Martin S.W. // J. Appl. Phys., 2000, vol. 88, p. 3113.

8. Qi Y., Cagin T., Kimura Y., Goddard III W.A. // Phys. Rev. B., 1999, vol. 59, p. 3527.

9. Sutton A.P., Chen J. // Philos. Mag. Lett., 1990, vol. 61, p. 139.

10. Allen M.P., Tildesley D.J. Computer Simulation of Liquids. Oxford, Clarendon Press, 1989.

11. Berendsen H.J.C., Postma J.P.M., Gunsteren W.F., DiNola A., Haak J.R. // J. Chem. Phys., 1984, vol. 81(8), p. 3684.

12. Morris J.R., Wang C.Z., Ho K.M., Chan C.T. // Phys. Rev. B., 1994, vol. 49, p. 3109.

13. Angell C.H. // Science, 1995, vol. 267, p. 1924.

14. Teichler H. // Def. Diff. Forum, 1997, vol. 143-147, p. 717; Phys. Rev. B., 1999, vol. 59, p. 8473.

15. Bakai A.S., Lazarev N.P., Ngai K.L. // MRS Proceedings, 2002, vol. 754, CC6.17. 
16. Jonsson H., Andersen H.C. // Phys. Rev. Lett., 1988, vol. 60, p. 2295; Clarke A.S., Jonsson H. // Phys. Rev. E., 1993, vol. 47, p. 3975.

17. Stillinger F.H., Weber T.A. // Science, 1984, vol. 225, p. 983.

18. Sheng H.W., He J.H., Ma E. // Phys. Rev. B., 2002, vol. 65, p. 184203.

19. Rahman A. // Phys. Rev. A., 1964, vol. 136, p. 405.

20. Gaukel C., Schober H.R. // Solid State Commun., 1998, vol. 107, p. 1.

21. Caprion D., Schober H.R. // Phys. Rev. B., 2000, vol. 62, p. 3709.

22. Kob W., Donati C., Plimpton S.J., Poole P.H., Glotzer S.C. // Phys. Rev. Lett., 1997, vol. 79 , p. 2827.

23. Ngai K.L., Rendell R.W., Leon C. // Phys. Rev. B., 2002, vol. 66, p. 064308.

24. Heuer A., Kunow M., Vogel M., Banhatti R. D. Preprint of arXiv.org e-Print archive, cond-mat/0205547, 2002.

\title{
Кооперативність, комірковий ефект та стрибкова дифузія в переохолодженій рідині і стеклах
}

\author{
О.С.Бакай, М.П.Лазарєв
}

Національний науковий центр

Харківський фізико-технічний інститут

61108 Харків, вул. Академічна, 1

Отримано 10 лютого 2003 р.

Методом молекулярної динаміки виконано моделювання структури та термодинамічних і кінетичних властивостей металевого сплаву $\mathrm{Ag}-\mathrm{Cu}$ з метою з'ясування його поведінки при переході рідина-скло. Незважаючи на незначні зміни структури потенціального рельєфу, релаксаційна кінетика зазнає драматичних змін при цьому переході. Залежність від часу середньоквадратичних віддалень атомів та параметру негаусовості виявляють ознаки аномальної дифузії в області проміжного часового масштабу. Аналіз еволюції в часі кореляційної функції Ван Гова виявляє наявність як стрибкових, так і кооперативних переміщень атомів. При температурах нижче $T_{\mathrm{g}}$ кооперативні переміщення не дають внеску в дифузію на велику відстань, але вони продовжують домінувати в короткочасних релаксаційних процесах.

Ключові слова: скляний перехід, металеві сплави, кооперативність, аномальна дифузія

PACS: 61.20.Ja, 61.20.Lc, 64.70.Pf 